\title{
O trokutu i kružnici u izotropnoj ravnini
}

Ivona Čatipović, Ema Jurkin, Željka Milin Šipuš

\section{Sažetak}

U radu se proučava elementarna geometrija izotropne ravnine. Definira se metrika te se proučavaju metričke relacije u trokutu. Dokazuju se teoremi o obodnom kutu, te o ortičkom i tangencijalnom trokutu vezani za trokut i kružnicu te se dobiveni rezultati uspoređuju s analognim tvrdnjama u euklidskoj ravnini. Nastao je iz diplomskog rada Ivone Čatipović, Geometrija izotropne ravnine.

Ključni pojmovi: izotropna ravnina, euklidska ravnina, udaljenost, kut, trokut, kružnica

MSC 2010: 51N25

\section{Uvod}

Neka su u koordinatnoj ravnini zadane točke $A\left(x_{A}, y_{A}\right), B\left(x_{B}, y_{B}\right)$. Promotrimo funkciju

$$
d(A, B)=\sqrt{\left(x_{B}-x_{A}\right)^{2}+\varepsilon\left(y_{B}-y_{A}\right)^{2}} .
$$

$\mathrm{Za} \varepsilon=1$, tom je funkcijom zadana euklidska udaljenost (metrika) točaka $A, B$, karakteristična za euklidsku geometriju ravnine koja se proučava tijekom osnovnoškolskog i srednjoškolskog obrazovanja. Funkciju $d: \mathbb{R}^{2} \times$ $\mathbb{R}^{2} \rightarrow \mathbb{R}$ koja točkama $A$ i $B$ pridružuje realan broj $d(A, B)$ nazivamo metrikom ako ona zadovoljava sljedeće aksiome:

(A1) $d(A, B) \geq 0, \quad \forall A, B \in \mathbb{R}^{2}$ 
(A2) $d(A, B)=0 \quad \Longleftrightarrow \quad A=B$

(A3) $d(A, B)=d(B, A), \quad \forall A, B \in \mathbb{R}^{2}$

(A4) $d(A, B) \leq d(A, C)+d(C, B), \quad \forall A, B, C \in \mathbb{R}^{2}$.

Ako je $\varepsilon=-1$, tada pripadna funkcija (1) nije metrika, jer ne zadovoljava npr. svojstvo (A2). Udaljenost dviju različitih točaka može biti nula, primjerice to su točke $A(0,0), B(1,1)$. Unatoč tome, njome se definira tzv. pseudometrika, te se pripadna geometrija ravnine naziva pseudoeuklidskom ili geometrijom Minkowskog. O temeljnim svojstvima Minkowskijeve ravnine može se pročitati u npr. [6].

Ako je pak $\varepsilon=0$, tada funkcija (1) također nije metrika. Kao i u prethodnoj situaciji, postoje različite točke čija je udaljenost jednaka 0 . To su općenito točke oblika $A\left(x_{A}, y_{A}\right), B\left(x_{A}, y_{B}\right)$. Pripadna geometrija naziva se izotropnom geometrijom. Cilj je ovog rada upravo proučiti temeljna svojstva te geometrije, te u njoj svojstva istaknutih figura, trokuta i kružnice. Uočit ćemo neke sličnosti i razlike ove ravnine s nama poznatom euklidskom ravninom.

U matematičkom obrazovanju nije neuobičajeno ni nemoguće posezati za "drugačijim” geometrijama ravnine. Neeuklidske geometrije u užem smislu, primjerice, hiperbolička geometrija, obično su ,izvan dosega" učenika. Inačica poznatog petog Euklidovog postulata za hiperboličku ravninu glasi da je zadanom točkom usporedno sa zadanim pravcem moguće povući više od jednog pravca. Među školskim izvankurikulskim temama iz geometrije koja nije euklidska, najčešće spominje tzv. taxicab geometrija ([3]), u kojoj se udaljenost među točkama računa kao $d(A, B)=\left|x_{B}-x_{A}\right|+\left|y_{B}-y_{A}\right|$. Tom je funkcijom zaista definirana metrika, specijalni slučaj tzv. $p$-metrike

$$
d(A, B)=\sqrt[p]{\left(x_{B}-x_{A}\right)^{p}+\left(y_{B}-y_{A}\right)^{p}} .
$$

\section{Osnovni pojmovi}

Već smo istaknuli da je izotropna udaljenost točaka oblika $A\left(x_{A}, y_{A}\right)$, $B\left(x_{A}, y_{B}\right)$ jednaka 0 i kada je $y_{A} \neq y_{B}$. Točkama tog oblika je u izotropnoj ravnini odreden jedan istaknuti smjer - u pripadnom je koordinatnom sustavu određen smjerom $y$-osi. Pravci s tim smjerom nazivaju se izotropnim pravcima. To su pravci zadani jednadžbama oblika $x=c$, $c \in \mathbb{R}$. Svaki neizotropan pravac $g$ ima jednadžbu oblika $y=k_{g} x+l_{g}$, $k_{g}, l_{g} \in \mathbb{R}, k_{g} \neq 0$. Kao i u euklidskoj ravnini za dva neizotropna pravca s jednadžbama $y=k_{g} x+l_{g}$ i $y=k_{h} x+l_{h}$ kažemo da su paralelni ako je $k_{g}=k_{h}$. Za razliku od euklidske ravnine, u izotropnoj ravnini postoji 
i pojam paralelnih točaka. To su točke koje leže na istom izotropnom pravcu. Dakle, točke $A\left(x_{A}, y_{A}\right)$ i $B\left(x_{B}, y_{B}\right)$ su paralelne ako je $x_{A}=x_{B}$.

Za dvije neparalelne točke $A\left(x_{A}, y_{A}\right)$ i $B\left(x_{B}, y_{B}\right)$ uobičajeno je definirati orijentiranu udaljenost $\mathrm{s} d(A, B)=x_{B}-x_{A}$. Udaljenost neparalelnih točaka je različita od 0 , dok je za paralelne točke ona jednaka 0 . Stoga se (ipak!) za dvije paralelne točke $A\left(x_{A}, y_{A}\right)$ i $B\left(x_{A}, y_{B}\right)$ definira dopunska udaljenost, tzv. raspon točaka $s(A, B)=y_{B}-y_{A}$, slika 1

$\mathrm{U}$ svakoj geometriji trebamo definirati i način na koji se mjeri kut. U euklidskoj geometriji, (radijanska) mjera kuta $\varphi$ između pravaca $g$ i $h \mathrm{~s}$ jednadžbama $y=k_{g} x+l_{g}$ i $y=k_{h} x+l_{h}$ izvodi se iz $\operatorname{tg} \varphi=\left|\frac{k_{h}-k_{g}}{1+k_{h} k_{g}}\right|$. $\mathrm{U}$ izotropnoj geometriji mjera kuta između neizoropnih pravaca definira se kao $\varphi(g, h)=k_{h}-k_{g}$. Udaljenost točaka i kut između pravaca $\mathrm{u}$ izotropnoj ravnini invarijate su tzv. grupe izometrija izotropne ravnine, kao što su te odgovarajuće veličine u euklidskoj geometriji invarijante (euklidskih) izometrija - rotacije, translacije, osne i centralne simetrije. Osim oznake $\varphi$, za mjeru kuta često se koristi i oznaka $\measuredangle$. Primijetimo da je mjera kuta između dva neparalelna pravca jednaka rasponu (paralelnih) točaka na zadanim pravcima koje su od sjecišta pravaca pomaknute za $x=1$. Za paralelne pravce $g$ i $h$ definirana je vrijednost $\varphi^{*}(g, h)=l_{h}-l_{g}$, slika 1. Uočimo da su sve četiri definirane vrijednosti orijentirane, tj. $d(B, A)=-d(A, B), s(B, A)=-s(A, B)$, $\varphi(h, g)=-\varphi(g, h), \varphi^{*}(h, g)=-\varphi^{*}(g, h)$.

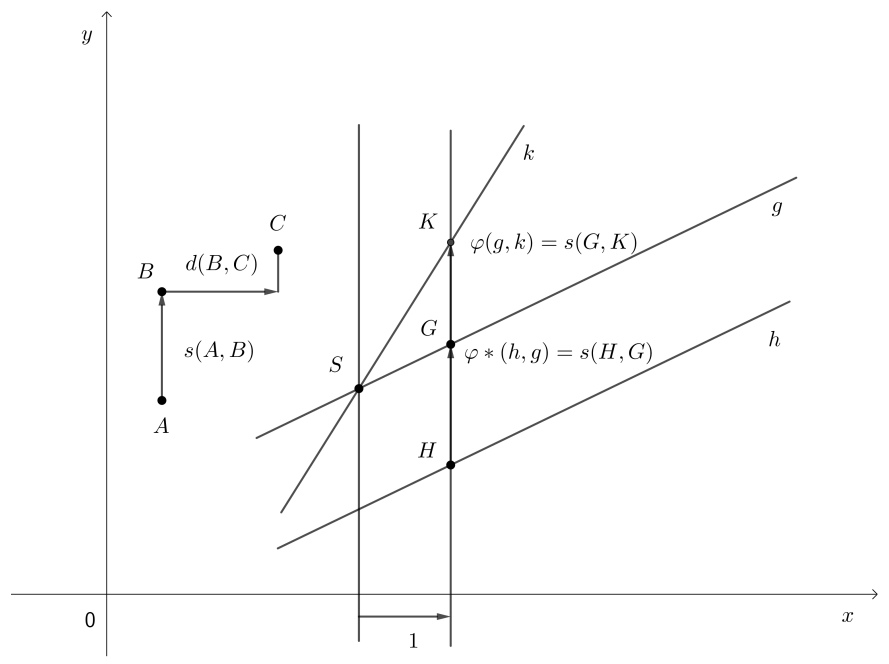

Slika 1: Udaljenost točaka i kut pravaca

U izotropnoj se ravnini ne definira okomitost, ali se definira normala 
neizotropnog pravca $p$ u nekoj točki $T$ kao izotropni pravac $n$ koji prolazi točkom $T$. Udaljenost $d(T, p)$ točke $T$ od pravca $p$ je raspon $s(N, P)$, gdje je $N$ točka pravca $p$ paralelna točki $T$.

Polovište $M$ neparalelnih točaka $A\left(x_{A}, y_{A}\right)$ i $B\left(x_{B}, y_{B}\right)$ je točka pravca $A B$ takva da $d(A, M)=d(M, B)$. Koordinate točke $M$ su

$$
\left(\frac{x_{A}+x_{B}}{2}, \frac{y_{A}+y_{B}}{2}\right) \text {. }
$$

Pojam polovišta $\mathrm{u}$ izotropnoj ravnini identičan je tom pojmu u euklidskoj ravnini. I njegove su koordinate dane istim izrazom.

Simetrala $s$ neparalelnih pravca $g$ i $h$ danih jednadžbama $y=k_{g} x+l_{g}$ i $y=k_{h} x+l_{h}$ je pravac koji prolazi njihovim sjecištem takav da $\varphi(g, s)=$ $\varphi(s, h)$. Jednadžba pravca $s$ je

$$
y=\frac{k_{g}+k_{h}}{2} x+\frac{l_{g}+l_{h}}{2} .
$$

Dakle, u izotropnoj ravnini dva neparalela pravca imaju samo jednu simetralu dok u euklidskoj ravnini dvije međusobno okomite simetrale raspolavljaju kut između dvaju neparalelnih pravaca.

\section{Trokut $u$ izotropnoj ravnini}

Trokut je figura koja se sastoji od triju točaka $A, B, C$, koje nazivamo vrhovima trokuta, i njihovih spojnica $A B, B C$ i $C A$ koje nazivamo stranicama trokuta. Ukoliko su vrhovi trokuta dani koordinatama

$$
A\left(x_{A}, y_{A}\right), \quad B\left(x_{B}, y_{B}\right), \quad C\left(x_{C}, y_{C}\right),
$$

stranice su dane jednadžbama

$$
\begin{aligned}
A B \quad \ldots \quad y & =\frac{y_{A}-y_{B}}{x_{A}-x_{B}} x+\frac{x_{A} y_{B}-x_{B} y_{A}}{x_{A}-x_{B}} \\
B C \quad \ldots \quad y & =\frac{y_{B}-y_{C}}{x_{B}-x_{C}} x+\frac{x_{B} y_{C}-x_{C} y_{B}}{x_{B}-x_{C}} \\
C A \quad \ldots \quad y & =\frac{y_{C}-y_{A}}{x_{C}-x_{A}} x+\frac{x_{C} y_{A}-x_{A} y_{C}}{x_{C}-x_{A}}
\end{aligned}
$$

U sljedeća su dva teorema istaknuta dva svojstva trokuta u izotropnoj ravnini koja se bitno razlikuju od svojstava trokuta u euklidskoj ravnini.

Teorem 1. Zbroj duljina stranica trokuta $A B C$ je 0.

Dokaz. Po definiciji udaljenosti točaka slijedi:

$d(A, B)+d(B, C)+d(C, A)=\left(x_{B}-x_{A}\right)+\left(x_{C}-x_{B}\right)+\left(x_{A}-x_{C}\right)=0$. 
Teorem 2. Zbroj mjera kutova u trokutu $A B C$ je 0.

Dokaz. Po definiciji kuta i iz izraza (3) slijedi:

$$
\begin{array}{r}
\varphi(C A, A B)+\varphi(A B, B C)+\varphi(B C, C A)=\left(\frac{y_{A}-y_{B}}{x_{A}-x_{B}}-\frac{y_{C}-y_{A}}{x_{C}-x_{A}}\right) \\
+\left(\frac{y_{B}-y_{C}}{x_{B}-x_{C}}-\frac{y_{A}-y_{B}}{x_{A}-x_{B}}\right)+\left(\frac{y_{C}-y_{A}}{x_{C}-x_{A}}-\frac{y_{B}-y_{C}}{x_{B}-x_{C}}\right)=0 .
\end{array}
$$

U euklidskoj se ravnini uz pojam trokuta redovito ističu i njegove četiri karakteristične točke. To su težište, ortocentar, sjecište simetrala kutova i sjecište simetrala stranice. Razmislimo sada mogu li se analogni pojmovi definirati i u izotropnoj ravnini i ako mogu, po čemu se oni razlikuju, odnosno u čemu se podudaraju s tim pojmovima u euklidskoj ravnini.

Kako je polovište stranice trokuta u izotropnoj ravnini definirano isto kao i u euklidskoj ravnini, i težišnice trokuta (spojnice vrha s polovištem nasuprotne stranice) bit će dane identičnim jednadžbama i sjeći će se u jednoj točki koju nazivamo težištem i koja ima koordinate $\left(\frac{x_{A}+x_{B}+x_{C}}{3}, \frac{y_{A}+y_{B}+y_{C}}{3}\right)$.

Promatramo vanjske i unutarnje kutove trokuta. U euklidskoj ravnini svakim vrhom trokuta prolaze dvije simetrale kutova trokuta. Tri simetrale unutarnjih kutova se sijeku u središtu upisane kružnice, dok se po dvije simetrale vanjskog kuta i jedna simetrala unutarnjeg kuta sijeku u središtima triju pripisanih kružnica. U izotropnoj ravnini svakim vrhom trokuta prolazi samo jedna simetrala. Te tri simetrale se ne sijeku u jednoj točki.

Pravcima analognim visinama trokuta smatramo izotropne pravce kroz vrhove trokuta. Ta se tri izotropna pravca ne sijeku u konačnosti (sijeku se u beskonačno dalekoj točki, odnosno paralelni su u euklidskom smislu) pa u izotropnoj ravnini ne možemo govoriti o ortocentru trokuta. Slično, pravcima analognim simetralama stranica smatramo izotropne pravce kroz polovišta stranica koji se opet ne sijeku u konačnosti.

\section{Kružnica u izotropnoj ravnini}

U euklidskoj je ravnini kružnica skup točaka ravnine jednako udaljenih od neke čvrste točke, njezinog središta. Jednadžba kružnice sa središtem $\left(x_{0}, y_{0}\right)$ i radijusom $r$ je $\left(x-x_{0}\right)^{2}+\left(y-y_{0}\right)^{2}=r^{2}$. Često je u dokazima, radi lakšeg računanja, translatiramo kako bi joj središte bilo u ishodištu koordinatnog sustava i ona imala jednadžu $x^{2}+y^{2}=r^{2}$. 
Ako bismo u izotropnoj ravnini kružnicu definirali analogno, dobili bismo dva izotropna pravca. Može se reći da je uobičajeno promatrati kružnicu koja dijeli s euklidskom kružnicom „ponašanje u beskonačnosti”, dakle, dira beskonačno daleki pravac u istaknutoj (tzv. apsolutnoj) točki, a ne onu koja bi se dobila analognom definicijom. Pokazuje se da koordinate $(x, y)$ točaka izotropne kružnice zadovoljavaju jednadžbu

$$
y=R x^{2}+\alpha x+\beta .
$$

Možemo reći da izotropna kružnica izgleda kao euklidska parabola čija je os paralelna s $y$-osi koordinatnog sustava. Broj $\frac{1}{2 R}$ nazivamo njezinim radijusom.

Kružnicu s jednadžbom (4) možemo translacijom

$$
\bar{x}=\frac{\alpha}{2 R}+x, \quad \bar{y}=\frac{\alpha^{2}}{4 R}-\beta+y
$$

smjestiti u koordinatni sustav tako da njezina jednadžba poprimi oblik

$$
y=R x^{2} .
$$

Dokažimo sada sljedeći teorem:

Teorem 3. Neka su dane točke $P$ i $Q$ kružnice $k$, te $t_{P}, t_{Q}$ tangente kružnice $k$ u tim točkama. Tada vrijedi

$$
\measuredangle\left(t_{P}, P Q\right)=R \cdot d(P, Q)=-\measuredangle\left(t_{Q}, P Q\right)
$$

$i$

$$
\measuredangle(A P, A Q)=R \cdot d(P, Q),
$$

gdje je A po volji odabrana točka kružnice $k$.

Dokaz. Neka je $y=R x^{2}$ jednadžba kružnice $k$. Tada točke $P, Q$ i $A$ imaju koordinate oblika $P\left(p, R p^{2}\right), Q\left(q, R q^{2}\right)$ i $A\left(a, R a^{2}\right)$. Jednadžbe pravaca $A P$ i $A Q$ su

$$
\begin{aligned}
& y=R(p+a) x-R p a \\
& y=R(q+a) x-R a q,
\end{aligned}
$$

dok su jednadžbe tangenata $t_{P}, t_{Q}$

$$
\begin{aligned}
& y=2 R p x-R p^{2} \\
& y=2 R q x-R q^{2} .
\end{aligned}
$$




\section{Vrijedi}

$$
\begin{aligned}
& \measuredangle\left(t_{P}, P Q\right)=R(q+p)-2 R p=R(q-p)=R \cdot d(P, Q) \\
& \measuredangle\left(t_{Q}, P Q\right)=R(q+p)-2 R q=R(p-q)=R \cdot d(Q, P)=-R \cdot d(P, Q)
\end{aligned}
$$

te

$$
\measuredangle(A P, A Q)=R(q+a)-R(p+a)=R(q-p)=R \cdot d(P, Q) .
$$

Pokazali smo, dakle, da je mjera kuta $\measuredangle(A P, A Q)$ konstantna, odnosno da ne ovisi o izboru točke $A$.

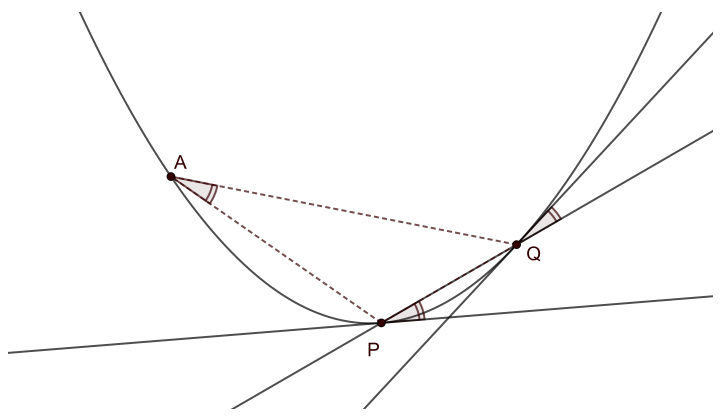

Slika 2: Vizualizacija teorema 3

Sjetimo se da i u euklidskoj ravnini vrijedi analogna tvrdnja ([4]): Neka je dana kružnica $k$, dvije točke $P$ i $Q$ kružnice $k$ te neka je točka $A$ točka kružnice $k, A \neq P, Q$. Tada vrijedi da je mjera svakog obodnog kuta $\measuredangle(P A Q)$ kružnice $k$ nad tetivom $P Q$ jednaka mjeri kuta između pravca $P Q$ i tangente kružnice $k$ u točkama $P$ ili $Q$, slika 3 .

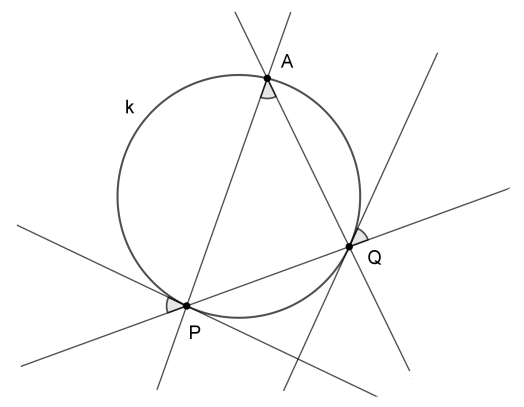

Slika 3: Teorem o obodnom kutu u euklidskoj ravnini 


\section{Trokut i kružnica u izotropnoj ravnini}

U ovom ćemo poglavlju na jednom primjeru istaknuti još neke sličnosti i razlike između euklidske i izotropne ravnine.

Krenemo li od nekog trokuta, različitim konstrukcijama možemo dobiti nove trokute čije su osobine vezane za osobine polaznog trokuta. Primjeri takvih trokuta su ortički i tangencijalni trokut. U euklidskoj ravnini ortički trokut $A_{H} B_{H} C_{H}$ trokuta $A B C$ je trokut kojemu su vrhovi sjecišta visina s nasuprotnim stranicama. Tangencijalni trokut $A_{T} B_{T} C_{T}$ trokuta $A B C$ je trokut čiji su vrhovi sjecišta tangenata $t_{A}, t_{B}, t_{C}$ opisane kružnice $k$ trokuta $A B C$ u njegovim vrhovima, slika 4 . Poznato je da odgovarajuće stranice tangencijalnog i ortičkog trokuta međusobno paralelne $([5])$.

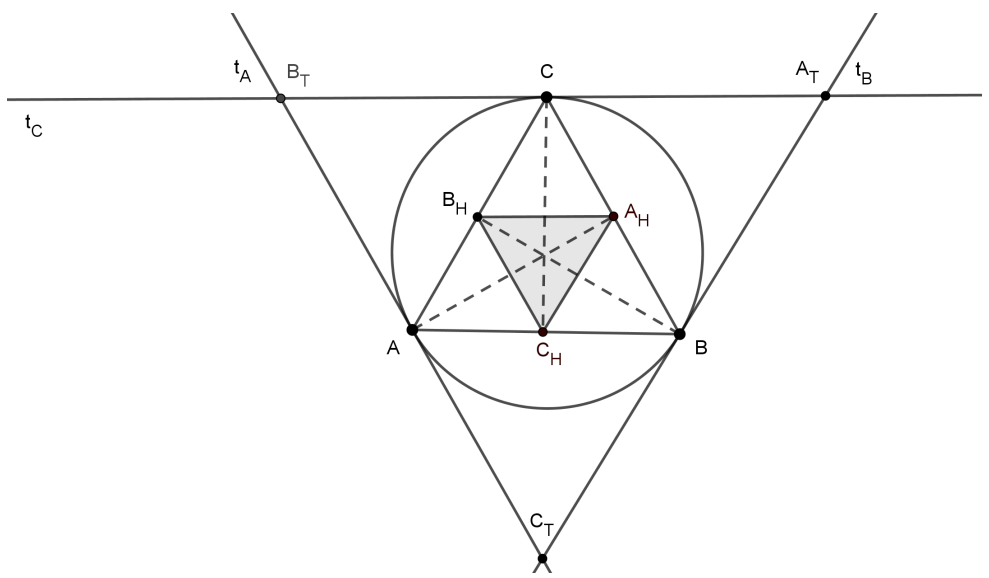

Slika 4: Ortički i tangencijalni trokuti trokuta $A B C$ u euklidskoj ravnini

Promotrimo sada analognu situaciju u izotropnoj ravnini, slika 5. U izotropnoj je ravnini ortički trokut $A_{H} B_{H} C_{H}$ trokuta $A B C$ definiran kao trokut čiji su vrhovi sjecišta izotropnih pravaca kroz vrhove trokuta $A B C$ s njima nasuprotnim stranicama. Vrhovi trokuta $A_{H} B_{H} C_{H}$ su dakle paralelni s vrhovima trokuta $A B C$. Tangencijalni trokut $A_{T} B_{T} C_{T}$ trokuta $A B C$ je definiran jednako kao i u euklidskoj ravnini, odnosno to je trokut čiji su vrhovi sjecišta tangenata $t_{A}, t_{B}, t_{C}$ opisane kružnice $k$ trokuta $A B C$ u vrhovima $A, B$ i $C$. Pokažimo sada da vrijedi sljedeći teorem:

Teorem 4. Neka su $A_{H} B_{H} C_{H} i A_{T} B_{T} C_{T}$ ortički i tangencijalni trokuti trokuta $A B C$ s opisanom kružnicom $k$. Tada vrijede sljedeće tvrdnje:

1) Vrhovi trokuta $A_{T} B_{T} C_{T}$ su paralelni s polovištima odgovarajućih 
stranica trokuta $A B C$ i pripadaju odgovarajućim stranicama ortičkog trokuta $A_{H} B_{H} C_{H}$.

2) Stranice trokuta $A_{T} B_{T} C_{T}$ su paralelne s odgovarajućim stranicama ortičkog trokuta $A_{H} B_{H} C_{H}$.

Dokaz. Neka je dana kružnica $k$ s jednadžbom $y=R x^{2}$ te njezine tri točke $A\left(a, R a^{2}\right), B\left(b, R b^{2}\right), C\left(c, R c^{2}\right)$. Vrhovi ortičkog trokuta $A_{H} B_{H} C_{H}$ trokuta $A B C$ su tada

$$
\begin{aligned}
& A_{H}(a, R(a c+a b-b c)), \\
& B_{H}(b, R(a b+c b-c a)), \\
& C_{H}(c, R(b c+a c-a b)) .
\end{aligned}
$$

Tangente $t_{A}, t_{B}, t_{C}$ kružnice $k \mathrm{u}$ točkama $A, B, C$ imaju redom jednadžbe

$$
\begin{array}{lll}
t_{A} & \ldots & y=2 R a x-R a^{2} \\
t_{B} & \ldots & y=2 R b x-R b^{2} \\
t_{C} & \ldots & y=2 R c x-R c^{2} .
\end{array}
$$

Odredimo koordinate vrhova trokuta $A_{T} B_{T} C_{T}$. Vrh $A_{T}$ je presjek tangenata $t_{B}$ i $t_{C}$ pa je $A_{T}\left(\frac{b+c}{2}, R b c\right)$. Stoga je točka $A_{T}$ paralelna s polovištem $P_{2}\left(\frac{b+c}{2}, \frac{R\left(b^{2}+c^{2}\right)}{2}\right)$ stranice $B C$. Slično se pokaže i da su vrhovi $B_{T}$ i $C_{T}$ paralelni s polovištima $P_{3}$ i $P_{1}$ stranica $A C$ i $A B$.

Jednadžbe stranica ortičkog trokuta su:

$$
\begin{array}{lll}
A_{H} B_{H} & \ldots & y=2 R c x+R(a b-b c-a c) \\
B_{H} C_{H} & \ldots & y=2 R a x+R(b c-a b-a c) \\
C_{H} A_{H} & \ldots & y=2 R b x+R(a c-b c-a b) .
\end{array}
$$

Jednostavnim računom možemo provjeriti da koordinate točaka $A_{T}, B_{T}$ i $C_{T}$ redom zadovoljavaju jednadžbe pravaca $B_{H} C_{H}, C_{H} A_{H}$ i $A_{H} B_{H}$. Time smo dokazali da vrhovi tangencijalnog trokuta $A_{T} B_{T} C_{T}$ leže na odgovarajućim stranicama ortičkog trokuta $A_{H} B_{H} C_{H}$.

Kako su $t_{A}, t_{B}$ i $t_{C}$ stranice tangencijalnog trokuta, odnosno $t_{A}=$ $B_{T} C_{T}, t_{B}=C_{T} A_{T}$ i $t_{C}=A_{T} B_{T}$, iz (6) i (7) je očito da vrijedi: $A_{T} B_{T} \|$ $A_{H} B_{H}, B_{T} C_{T} \| B_{H} C_{H}$ i $A_{T} C_{T} \| A_{H} C_{H}$. 


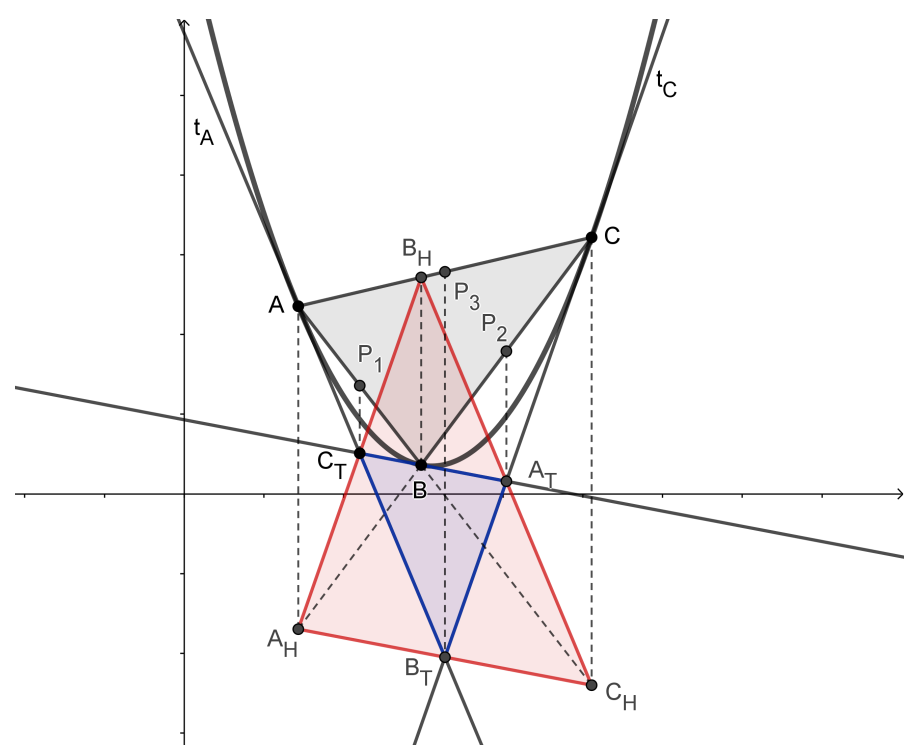

Slika 5: Ortički i tangencijalni trokuti trokuta $A B C$ u izotropnoj ravnini

\section{Literatura}

[1] I. Čatipović, Geometrija izotropne ravnine, Diplomski rad, Prirodoslovno-matematički fakultet, Zagreb, 2018. https:// repozitorij.pmf.unizg.hr/islandora/object/pmf\%3A5121/

[2] R. Kolar-Šuper, Z. Kolar-Begović, V.Volenec, J. Beban-Brkić, Metrical relationships in a standard triangle in an isotropic plane, Math. Commun. 10 (2005), 149-157.

[3] E. F. Krause, Taxicab Geometry: An Adventure in Non-Euclidean Geometry, Dover Books on Mathematics, 1986.

[4] D. Palman, Planimetrija, Element, Zagreb, 1999.

[5] D. Palman, Trokut i kružnica, Element, Zagreb, 2004.

[6] Ž. Milin Šipuš, R. Capor, Geometrija Minkowskog, Matematičkofizički list, 3/231 (2008) 161-167.

[7] H. Sachs, Ebene Isotrope Geometrie, Wieweg, BraunschweigWiesbaden, 1987. 
Ivona Čatipović

Sveučilište u Zagrebu, Prirodoslovno-matematički fakultet, Bijenička 30, 10000 Zagreb, Hrvatska

E-mail adresa: ivona.catipovic@gmail.com

Ema Jurkin

Sveučilište u Zagrebu, Rudarsko-geološko-naftni fakultet, Pierottijeva 6, 10000 Zagreb, Hrvatska

E-mail adresa: ema.jurkin@rgn.hr

Željka Milin Šipuš

Sveučilište u Zagrebu, Prirodoslovno-matematički fakultet, Bijenička 30, 10000 Zagreb, Hrvatska

E-mail adresa: zeljka.milin-sipus@math.hr

Zaprimljen: 15 . veljače 2019.

Prihvaćen: 15. travnja 2019. 